\title{
BMJ Open Effect of investigation intensity and treatment differences on prostate cancer survivor's physical symptoms, psychological well-being and health-related quality of life: a two country cross-sectional study
}

\author{
Anna T Gavin, ${ }^{1}$ David Donnelly, ${ }^{1}$ Conan Donnelly, ${ }^{1}$ Frances J Drummond, ${ }^{2}$ \\ Eileen Morgan, ${ }^{1}$ Gerard J Gormley, ${ }^{3}$ Linda Sharp ${ }^{4}$
}

To cite: Gavin AT,

Donnelly D, Donnelly $\mathrm{C}$, et al. Effect of investigation intensity and treatment differences on prostate cancer survivor's physical symptoms, psychological well-being and health-related quality of life: a two country cross-sectional study. BMJ Open 2016;6:e012952. doi:10.1136/bmjopen-2016012952

- Prepublication history and additional material is available. To view please visit the journal (http://dx.doi.org/ 10.1136/bmjopen-2016012952).

Received 6 June 2016 Revised 31 August 2016 Accepted 20 October 2016

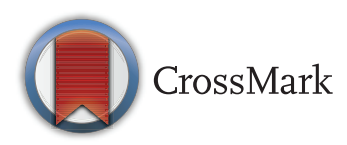

For numbered affiliations see end of article.

Correspondence to Dr Anna T Gavin; a.gavin@qub.ac.uk

\section{ABSTRACT}

Aim: To investigate effects on men's health and wellbeing of higher prostate cancer ( $\mathrm{PCa}$ ) investigation and treatment levels in similar populations.

Participants: PCa survivors in Ireland where the Republic of Ireland (Rol) has a 50\% higher PCa incidence than Northern Ireland (NI).

Method: A cross-sectional postal questionnaire was sent to $\mathrm{PCa}$ survivors 2-18 years post-treatment, seeking information about current physical effects of treatment, health-related quality of life (HRQoL; EORTC QLQ-C30; EQ-5D-5L) and psychological well-being (21 question version of the Depression, Anxiety and Stress Scale, DASS-21). Outcomes in Rol and NI survivors were compared, stratifying into 'late disease' (stage III/ IV and any Gleason grade (GG) at diagnosis) and 'early disease' (stage I/II and GG 2-7). Responses were weighted by age, jurisdiction and time since diagnosis. Between-country differences were investigated using multivariate logistic and linear regression.

Results: 3348 men responded (Rol $\mathrm{n}=2567$; NI $\mathrm{n}=781$; reflecting population sizes, response rate $54 \%$ ). Rol responders were younger; less often had comorbidities ( $45 \%$ vs $38 \%$ ); were more likely to present asymptomatically $(66 \% ; 41 \%)$ or with early disease $(56 \% ; 35 \%)$; and less often currently used androgen deprivation therapy (ADT; $2 \% ; 28 \%)$. Current prevalence of incontinence (16\%) and impotence (56\% early disease, $67 \%$ late disease) did not differ between Rol and NI. In early disease, only current bowel problems (Rol 12\%; NI 21\%) differed significantly in multivariate analysis. In late disease, NI men reported significantly higher levels of gynaecomastia ( $23 \%$ vs $9 \%$ ) and hot flashes ( $41 \%$ vs $19 \%$ ), but when ADT users were analysed separately, differences disappeared. For HRQoL, in multivariate analysis, only pain (early disease: Rol 11.1, NI 19.4) and financial difficulties (late disease: Rol 10.4, NI 7.9) differed

\section{Strengths and limitations of this study}

This large study used the same approaches in both geographical areas for patient definition, recruitment, data collection and analysis with validated instruments used to assess patientreported outcomes. Also, men were categorised for analysis by stage and grade of disease to help compensate for differences in the patient profile of the two populations.

- High-quality population-based cancer registries provided the basis for sampling allowing population representativeness to be assessed and proportions weighted to the entire survivor population.

- Lack of information on baseline health at diagnosis and symptoms at diagnosis are potential limitation and we acknowledge this could be more of a problem with the older Northern Ireland (NI) population and for men diagnosed longer ago; however, health and health-related quality of life (HRQoL) effects were measures as reported currently.

- While the categorisation into early and late disease was loosely based on D'Amico criteria, PSA levels at diagnosis were not systematically available and Gleason scores were recorded in the registries as a categorical variable, with a cut-off at 7.

- We did not collect data from men in the population without prostate cancer (ie, normative data), so we cannot be sure that the background prevalence of physical symptoms, such as ED, or levels of HRQoL or psychological well-being does not differ between $\mathrm{NI}$ and Republic of Ireland. (A normative study is, however, underway.) 
significantly between countries. There were no significant betweencountry differences in DASS-21 or index ED-5D-5L score.

Conclusions: Treatment side effects were commonly reported and increased PCa detection in Rol has left more men with these side effects. We recommended that men be offered a PSA test only after informed discussion.

\section{INTRODUCTION}

Age-standardised prostate cancer (PCa) incidence has increased over the past two decades associated with increased use of PSA testing, ${ }^{1}$ so that now in many countries it is the most common cancer among males. ${ }^{2}$ The debate about the value of PSA testing for the early detection of PCa continues. While a simple blood test and the prospect of earlier cancer diagnosis are appealing, poor specificity leads to overdiagnosis of clinically insignificant cancers. ${ }^{3}$ To be considered effective, screening must reduce overall and disease-specific mortality and morbidity and not just detect more disease. Only one large long-term randomised controlled trial has identified a significant reduction in deaths associated with Prostate Specific Antigen (PSA) 'screening', but this was accompanied by a high level of overdiagnosis and associated treatment. ${ }^{4}$ Despite this, marked international variations in $\mathrm{PCa}$ incidence rates point to widespread use of PSA testing for unsuspected $\mathrm{PCa}^{2}$ and recent calls to offer men in their $40 \mathrm{~s}$ access to the PSA test is likely to further increase numbers diagnosed. ${ }^{5}$ In the light of this, and in order to inform the PSA debate, it would be of value to determine whether more investigation and treatment improves men's self-reported health outcomes, especially in the long term.

Circumstances exist in Ireland where different intensities of PSA testing and subsequent biopsy between its two jurisdictions, Republic of Ireland (RoI) and Northern Ireland (NI), exist in populations which are similar in lifestyle and ethnic and genetic makeup. ${ }^{6}$ Both jurisdictions have high-quality population-based cancer registries which have tracked PCa incidence since the early 1990s. ${ }^{7} 8$ The RoI has a complex mixed public-private healthcare system and rates of PSA testing in men aged 50 and older rose by $23 \%$ per annum between 1993 and 2005. ${ }^{6}$ In 2006, the National Cancer Forum recommended against the introduction of PSA screening; however, high levels of testing persisted. ${ }^{9}$ In contrast, NI has a predominantly publicly funded healthcare system similar to the NHS and has encouraged following the National Screening Committee's advice in 2002 and the National Institute for Health and Care Excellence (NICE) guidelines (2008) aimed at limiting the use of PSA testing in primary care. ${ }^{10}{ }^{11}$ Nevertheless, there is evidence of screening for PCa in the NI population, ${ }^{12}$ although at markedly lower levels (annual percentage change 1993 to $2003=+9.7 \%$ ) than in RoI. ${ }^{6}$ Consequently, since 1994, when PCa incidence rates were similar, the age-standardised incidence rate has risen by $222 \%$ in RoI compared with $161 \%$ in NI. These unique circumstances allow us to investigate the effect of more intense investigation and treatment of PCa on men's health and well-being.

\section{METHODS}

This work was undertaken as part of the PiCTure (Prostate Cancer Treatment, your experience) study, which was conducted in RoI and NI, the methods of which have been described previously ${ }^{13}$ and in short are described below.

\section{Patient involvement}

Patients were involved in study steering group, piloting of questionnaire and interpretation of results.

\section{Participants/patients}

Following ethical approvals, a population-based sample of all men diagnosed with invasive $\mathrm{PCa}$ (International Classification of Diseases (ICD10 C61) between 1 January 1995 and 31 March 2010, and alive in November 2011, was selected from the two populationbased cancer registries $(n=22823)$. From this, a country and time (with approximately the same numbers under and over 5 years since diagnosis) stratified random sample of 12322 men was selected. This was required as there were fewer survivors diagnosed in the earlier years for two reasons: one, the levels of $\mathrm{PCa}$ diagnosed were lower; and second, since at least $50 \%$ of PCa cases are over 70 when diagnosed, so mortality would have reduced numbers.

Patients' general practitioners/healthcare professionals were contacted to screen men for eligibility to participate in the study. Men were eligible if they were (1) alive, (2) aware of their PCa diagnosis, (3) well enough to receive and complete a questionnaire (in particular, had no cognitive impairment), (4) able to understand English and (5) resident in RoI or NI. Following this process, $6559 \mathrm{PCa}$ survivors were deemed eligible to be sent a questionnaire. Questionnaires were posted in 2012. Non-responders received up to two written reminders.

\section{Outcome measures}

The primary outcome variables for this analysis were determined by questionnaire and were

1. PCa-related physical symptoms 'currently' experienced (ie, present at time of questionnaire completion; erectile dysfunction (ED), urinary incontinence, bowel problems, loss of libido, gynaecomastia and hot flashes/sweats).

2. Health utility on the day of questionnaire completion, measured by the 5 level health status measure EQ-5D-5L which comprises five dimensions: mobility, self-care, usual activities, pain/discomfort and anxiety/depression. Each dimension has five possible levels of response: no problems, slight, moderate, severe or 
unable to undertake the particular action. The EQ-5D-5L health states were converted to EQ-5D-3L states and UK valuations applied to provide a single index value of up to 1 (since there are no valuations specifically for Ireland and NI is part of the UK) ${ }^{14}{ }^{15}$ higher values indicate better/more health utility.

3. Health-related quality of life (HRQoL) in the past week measured using the European Organisation for Research and Treatment of Cancer - Quality of Life Questionnaire (EORTC QLQ)-C30 ${ }^{16}$ a general cancer questionnaire comprising a global health score (GHS), five functional subscales (measuring physical, role, emotional, cognitive and social functioning) and nine general cancer symptom subscales (assessing fatigue, nausea/vomiting, pain, dyspnoea, sleep disturbance, loss of appetite, constipation, diarrhoea and financial difficulties). Response options range from 1 (not at all) to 4 (very much), except for the two questions comprising the GHS, responses to which ranged from 1 (very poor) to 7 (excellent). Scores on each subscale were transformed to $0-100$ as recommended, with higher scores indicating better HRQoL, higher functioning or worse symptoms). ${ }^{16}$

4. Psychological well-being during the past week, assessed by the 21 question version of the Depression, Anxiety and Stress Scale (DASS-21) ${ }^{17}$ which contains three subscales which measure depression, anxiety and (di) stress. Each subscale is based on seven questions with responses scored from 0 (did not apply) to 3 (applied to me very much, or most of the time). A summary score for each subscale was generated by doubling the sum of the individual responses. Possible scores on each scale range from 0 to 42, with higher scores indicating higher levels of depression, anxiety or stress.

\section{Explanatory variables}

Men were asked to report all treatments received, by answering yes/no to a list of treatments (radical prostatectomy (RP), external beam radiotherapy (EBRT), androgen deprivation therapy (ADT), active surveillance (AS), watchful waiting (WW) and brachytherapy (BT)). The questionnaire also requested information on sociodemographic characteristics, method of diagnosis ('symptomatic clinically detected' or 'asymptomatic PSA detected' $)^{13}$ and health at diagnosis, in particular urinary (increase in frequency, pain while urinating, blood in urine) or sexual (impotence/erectile dysfunction) symptoms (yes/no) and presence of comorbidities (which men were invited to select from a list comprising heart or lung disease, stroke, diabetes, high blood pressure, diverticular disease, bowel problems (eg, constipation/diarrhoea), other cancer, depression or other).

Date of diagnosis, stage at diagnosis (tumour-lymph node-metastasis classification) and Gleason grade (GG) for all men who were sent questionnaires were extracted from the cancer registries. GG is collected by the RoI cancer registry National Cancer Registry Ireland,
(NCRI) as a categorical variable (low (GG 2-4), medium (GG 5-7) or high grade (GG 8-10), so these categories were used in analysis. Supplementary staging information was abstracted from medical records for NI respondents in early years when staging levels in the N. Ireland Cancer Registry (NICR) were low.

\section{Statistical analysis}

The goal of the analysis was to compare health and wellbeing between men from RoI and NI. However, the characteristics of the populations of patients with $\mathrm{PCa}$ and therefore the populations of survivors and respondents differed between RoI and NI, notably in the proportions of early and late disease. To overcome this, and since disease extent at diagnosis is likely to be an important determinant of health and well-being, analyses adjusted for sociodemographic and clinical characteristics were undertaken and outcomes were analysed separately for two main categories: 'late disease' defined as stage III or IV and any GG at diagnosis and 'early disease' defined as stage I/II and GG 2-7 at diagnosis. A third group, 'other', which included those without stage or grade or with early stage and high grade, was also created and summary findings are reported for completeness.

Survey responses were weighted by age, country and time since diagnosis to compensate for higher nonresponse in certain survivor subgroups ${ }^{13}$ and increase representativeness of the results to the entire PCa survivor population.

Differences in proportions of patient characteristics, symptom and functional scores and DASS-21 subscales between survivors from NI and RoI were tested using z-tests and $\chi^{2}$ tests for early and late disease separately. Multivariate regression models (logistic for physical symptoms and linear for health utility, HRQoL and psychological well-being) were developed using a staged approach. The first model adjusted for age at questionnaire completion, number of comorbidities at diagnosis, time since diagnosis and method of diagnosis (model 1). The second model (model 2) then added treatments (RP, EBRT, BT, ADT) since treatment usage differs between RoI and NI. Records with missing treatment or method of diagnosis were dropped from all models $(n=60)$.

Significance was at the $5 \%$ level with the Bonferroni correction applied to compensate for multiple comparisons (see table footnotes for details of significance levels for each analysis).

\section{RESULTS}

In total, 3348 men responded, providing a $54 \%$ overall response rate after adjustment for men who were discovered to be ineligible following questionnaire dispatch. Seventy per cent of responders were from RoI $(n=2567)$ and $30 \%(\mathrm{n}=781)$ from NI, reflecting the different country population numbers.

Almost half of the respondents $(48 \%)$ were surveyed 2-4.9 years postdiagnosis, $32 \%$ were surveyed $5-9.9$ years 
and $20 \%$ were surveyed $\geq 10$ years after diagnosis. Respondents' average age at diagnosis was 64.9 years (SD 7.6). Men from RoI were younger, more often reported asymptomatic PSA detection of their cancer and more often presented without urinary symptoms or without comorbidities compared with respondents from NI (all $\mathrm{p}<0.001)$. Respondents from NI more often reported having ADT or EBRT, and less often having RP or BT compared with respondents from RoI (table 1).

Overall, $51 \%$ of respondents $(n=1700)$ were classified as early stage disease at diagnosis. Early disease survivors accounted for $56 \%$ of RoI respondents $(\mathrm{n}=1431)$ and $35 \%$ of NI respondents $(n=269)$. Overall, $21 \%$ of respondents had late disease $(\mathrm{n}=689)$, and this comprised $36 \%$ of NI responders $(\mathrm{n}=282)$ and $16 \%$ of RoI responders $(n=407)$. This left 959 (29\% overall) in the 'other' group, representing an almost identical percentage of respondents from RoI (28\%) and NI (29\%).

\section{Men with early disease at diagnosis}

There were no differences between early disease patients in NI and RoI in terms of age or comorbidities at diagnosis, current age, marital status, or (not shown) living alone and family history. Responders with early disease from RoI were more likely to have been diagnosed 510 years previously ( $46 \%$ vs $35 \%$ ); more often asymptomatic PSA-detected; more often treated with RP; less often treated with EBRT, ADT or AS/WW and more likely to report no symptoms at diagnosis. Men from NI were more often diagnosed in the previous 2-5 years and more likely to report increased frequency of urination at diagnosis (all $\mathrm{p}<0.001$; table 1 ).
There were no significant differences between early disease patients from NI and RoI in reported 'current' PCa-related physical symptoms for urinary incontinence (overall weighted percentage, $15 \%$ ), libido loss (42\%), erectile dysfunction (56\%), breast changes $(5 \%)$, hot flashes $(9 \%)$ or reporting at least one physical symptom $(76 \%)$. Significant differences existed in univariate analysis for bowel problems and fatigue, both of which were more common in NI (table 2). In multivariate analysis adjusting for age, comorbidities, time since diagnosis and method of diagnosis (model 1), these differences remained significant. When treatment was added (model 2), only bowel problems remained significant (OR $1.8,95 \%$ CI 1.26 to 2.56 , $\mathrm{p}=0.001$; table 2 ).

For health utility and HRQoL, better outcomes among men from RoI than NI were suggested in univariate analysis by higher scores for EQ-5D-5L, QLQ-C30 physical and role functioning and lower scores for QLQ-C30 fatigue, pain dyspnoea and insomnia. Apart from physical functioning and insomnia, these differences remained significant in multivariate model 1; however, only pain (which was higher for men from NI) remained significant when treatment was added (model 2; RoI 11.1, NI 19.4, coefficient 5.829, CI 2.349 to 9.308, $\mathrm{p}=0.001$; table 2). In terms of psychological well-being, there were no significant differences between RoI and NI for depression, anxiety or distress scores in univariate or multivariate analysis (table 3 ).

\section{Men with late disease at diagnosis}

There were no differences in current age, time since diagnosis, family history of $\mathrm{PCa}$ or specific comorbidities

Table 1 Characteristics of men and treatment received by disease category and jurisdiction (weighted proportions)

\begin{tabular}{|c|c|c|c|c|c|c|}
\hline & \multicolumn{2}{|c|}{ Early disease* } & \multicolumn{2}{|c|}{ Late disease† } & \multicolumn{2}{|c|}{$\begin{array}{l}\text { All respondents } \\
\text { (includes those } \\
\text { classified as 'other') }\end{array}$} \\
\hline & Rol & NI & Rol & NI & Rol & NI \\
\hline Weighted numbers & 1431 & 269 & 407 & 282 & 2567 & 781 \\
\hline Age at diagnosis $>70$ years & $27.6 \%$ & $32.9 \%$ & $30.3 \%$ & $38.4 \%$ & $32.4 \% \ddagger$ & $40 \% \ddagger$ \\
\hline Age at diagnosis $<60$ years & $25.2 \%$ & $21.8 \%$ & $25.6 \% \ddagger$ & $15 \% \ddagger$ & $22.8 \% \ddagger$ & $17.4 \% \ddagger$ \\
\hline Symptomatic clinically detected & $28.3 \% \ddagger$ & $51.4 \% \ddagger$ & $37.5 \ddagger$ & $59.0 \ddagger$ & $32.3 \% \ddagger$ & $58.2 \% \ddagger$ \\
\hline Asymptomatic PSA detected & $70.2 \% \ddagger$ & $48.4 \% \ddagger$ & $61.3 \% \ddagger$ & $40.4 \% \ddagger$ & $66.2 \% \ddagger$ & $41.1 \% \ddagger$ \\
\hline No symptoms at diagnosis & $38.3 \% \ddagger$ & $24.2 \% \ddagger$ & $35.8 \% \ddagger$ & $23.8 \% \ddagger$ & $36.7 \% \ddagger$ & $23.0 \% \ddagger$ \\
\hline Urinating more frequently at diagnosis & $45.9 \% \ddagger$ & $64.3 \% \neq$ & $45.0 \% \ddagger$ & $58.3 \% \ddagger$ & $47.5 \% \ddagger$ & $62.7 \% \ddagger$ \\
\hline No comorbidities at diagnosis & $45.4 \%$ & $39.0 \%$ & $51.2 \% \ddagger$ & $34.9 \% \ddagger$ & $45.2 \% \ddagger$ & $38.0 \% \ddagger$ \\
\hline Radical prostatectomy & $34.8 \% \ddagger$ & $15.7 \% \ddagger$ & $39.2 \%$ & $10.5 \% \ddagger$ & $30.9 \% *$ & $13.9 \% \ddagger$ \\
\hline External beam radiotherapy & $51.5 \% \ddagger$ & $64.4 \% \ddagger$ & $64.1 \% \ddagger$ & $79.1 \% \ddagger$ & $55.7 \% \ddagger$ & $64.1 \% \ddagger$ \\
\hline Brachytherapy & $7.4 \%$ & $4.9 \%$ & $3.2 \%$ & $0 \%$ & $6.6 \% \ddagger$ & $1.8 \% \ddagger$ \\
\hline Androgen deprivation therapy (ever) & $27.9 \% \neq$ & $60.0 \% \ddagger$ & $52.5 \% \ddagger$ & $87.1 \% \ddagger$ & $37.3 \% \ddagger$ & $71.9 \% \ddagger$ \\
\hline Chemotherapy & $1 \%$ & $0.3 \%$ & $3.8 \%$ & $3.7 \%$ & $2 \%$ & $1.8 \%$ \\
\hline Active surveillance/watchful waiting & $5 \% \ddagger$ & $10.2 \% \neq$ & $1.3 \%$ & $0.2 \%$ & $4.7 \%$ & $5.7 \%$ \\
\hline No treatment & $2.9 \%$ & $1.8 \%$ & $2.0 \%$ & $0.0 \%$ & $3.2 \%$ & $2.5 \%$ \\
\hline \multicolumn{7}{|c|}{$\begin{array}{l}\text { Results are weighted by country, age at diagnosis and time since diagnosis. } \\
{ }^{*} \text { Early=stage I/II Gleason grade } 2-7 . \\
\text { †Late=stage III/IV any Gleason grade. } \\
\text { ¥Significant difference at (notional } p<0.05, p<0.001 \text { with Bonferroni correction applied). } \\
\text { NI, Northern Ireland; Rol, Republic of Ireland. }\end{array}$} \\
\hline
\end{tabular}


Table 2 Prostate cancer-related physical symptoms-early disease patients

\begin{tabular}{|c|c|c|c|c|c|}
\hline \multicolumn{3}{|c|}{ Stage $1 / I I-$ Gleason grade $2-7$} & \multirow{3}{*}{$\begin{array}{l}\text { Univariate model } \\
\text { OR } \\
\text { (NI vs Rol) } \\
\text { (Rol as baseline) }\end{array}$} & \multirow{3}{*}{$\begin{array}{l}\text { Multivariate model } 1^{*} \\
\text { OR } \\
\text { (NI vs Rol) } \\
\text { (Rol as baseline) }\end{array}$} & \multirow{3}{*}{$\begin{array}{l}\text { Multivariate model } 2 \dagger \\
\text { OR } \\
\text { (NI vs Rol) } \\
\text { (Rol as baseline) } \\
\end{array}$} \\
\hline \multirow{2}{*}{$\begin{array}{l}\text { Ongoing side } \\
\text { effects }\end{array}$} & \multicolumn{2}{|c|}{$\begin{array}{l}\text { Weighted } \\
\text { proportion }\end{array}$} & & & \\
\hline & Rol (\%) & NI (\%) & & & \\
\hline continence & 3 & & $\begin{array}{l}1.26 \\
(0.90 \text { to } 1.74) p=0.173\end{array}$ & $\begin{array}{l}1.12 \\
(0.81 \text { to } 1.56) p=0.485\end{array}$ & $\begin{array}{l}1.43 \\
(0.99 \text { to } 2.07) p=0.057\end{array}$ \\
\hline Loss of libido & 41.3 & 48.0 & $\begin{array}{l}1.27 \\
(0.98 \text { to } 1.64) p=0.068\end{array}$ & $\begin{array}{l}1.30 \\
(1.00 \text { to } 1.69) p=0.046\end{array}$ & $\begin{array}{l}1.20 \\
(0.91 \text { to } 1.59) p=0.198\end{array}$ \\
\hline Erectile dysfunction & 56.1 & 56.9 & $\begin{array}{l}1.01 \\
(0.78 \text { to } 1.30) p=0.950\end{array}$ & $\begin{array}{l}1.16 \\
(0.88 \text { to } 1.52) p=0.289\end{array}$ & $\begin{array}{l}1.24 \\
(0.92 \text { to } 1.68) p=0.163\end{array}$ \\
\hline Bowel problems & 11.5 & 21.1 & $\begin{array}{l}2.07 \ddagger \\
(1.49 \text { to } 2.89) p<0.001\end{array}$ & $\begin{array}{l}1.87 \ddagger \\
\text { (1.32 to } 2.64) p<0.001\end{array}$ & $\begin{array}{l}1.80 \ddagger \\
(1.26 \text { to } 2.56) p=0.001\end{array}$ \\
\hline $\begin{array}{l}\text { Breast changes } \\
\text { (gynaecomastia) }\end{array}$ & 4.6 & 7.9 & $\begin{array}{l}1.78 \\
\text { (1.12 to } 2.83) p=0.015\end{array}$ & $\begin{array}{l}1.63 \\
(1.02 \text { to } 2.59) p=0.042\end{array}$ & $\begin{array}{l}0.93 \\
(0.56 \text { to } 1.54) p=0.772\end{array}$ \\
\hline Hot flashes & 8.4 & 10.9 & $\begin{array}{l}1.30 \\
(0.87 \text { to } 1.94) p=0.199\end{array}$ & $\begin{array}{l}1.15 \\
(0.76 \text { to } 1.74) p=0.503\end{array}$ & $\begin{array}{l}0.70 \\
(0.44 \text { to } 1.13) p=0.144\end{array}$ \\
\hline Fatigue & 17.0 & 28.7 & $\begin{array}{l}1.98 \ddagger \\
\text { (1.47 to } 2.66) p<0.001\end{array}$ & $\begin{array}{l}1.76 \ddagger \\
\text { (1.30 to } 2.39) p<0.001\end{array}$ & $\begin{array}{l}1.53 \\
(1.12 \text { to } 2.10) p=0.008\end{array}$ \\
\hline
\end{tabular}

Results are weighted by country, age at diagnosis and time since diagnosis.

*Logistic regression model adjusted for age at questionnaire completion, number of comorbidities at diagnosis, time since diagnosis and method of diagnosis.

†Logistic regression model adjusted for the above plus prostatectomy, external beam radiotherapy, brachytherapy and hormone therapy records with missing treatment or method of diagnosis dropped from all models $(n=60)$. Significant difference at $p<0.05$ but with Bonferroni correction applied.

$¥$ Significant difference between countries.

NI, Northern Ireland; Rol, Republic of Ireland.

at diagnosis between RoI and NI men with late disease (not shown). Responders with late disease from the RoI more often were under age 60 at diagnosis and reported no comorbidities at diagnosis. Men with late disease from NI more often reported urinating more frequently at diagnosis; they also more often presented symptomatically, were less often treated with RP and were more often treated with EBRT or ADT (all $\mathrm{p}<0.001$ table 1 ).

In terms of physical cancer-related symptoms in men with late disease, there were no significant differences for ongoing urinary incontinence (overall weighted percentage $20 \%$ ), erectile dysfunction $(67 \%)$ or bowel problems (17\%) between men from NI and RoI. Loss of libido, breast changes, hot flashes and fatigue were significantly more frequently reported in men from NI. These differences remained after adjustment for age, comorbidities, time since diagnosis and method of diagnosis (model 1$)$, but when treatment was added to the model (model 2) only breast changes (OR 2.3, 95\% CI 1.41 to 3.73 ) and hot flashes (OR 2.33, 95\% CI 1.55 to 3.51) remained significant, although the ORs were attenuated (table 4).

For health utility, HRQoL and psychological wellbeing, only QLQ-C30 financial difficulties scores differed significantly in multivariate analyses (RoI 17.9 vs NI 10.4; model 2: coefficient $=8.629$, CI -12.770 to 4.488 , $\mathrm{p}<0.001 ;$ table 5$)$.

\section{'Other' group}

Of the 'other' group ( $\mathrm{n}=959), 300$ had stage I/II highgrade (8-10) disease, and the remainder had either unknown stage $(n=171)$ and/or unknown grade $(n=372$; for 116, both were unknown). There were no significant differences between responders from NI and RoI for any outcomes in the fully adjusted multivariate model (model 2; see online supplementary table S1).

\section{DISCUSSION}

Using data from this large sample of PCa survivors of all ages and those who had received all forms of treatment, we compared men's reported physical symptoms, psychological well-being, health utility and HRQoL between two countries with different policies and practices in relation to PCa detection. This unique set of circumstances-where clinicians in RoI undertake more PSA testing of asymptomatic men in primary care and refer more men to hospital for prostate biopsy, resulting in a considerably higher incidence of PCa than in NI-has resulted in differences between countries in the profile of PCa, in terms of the sociodemographic characteristics of the men diagnosed, the distribution of disease stage and grade, and patterns of treatment usage ${ }^{6}$ By examining patients with early and late disease separately, we are able to compare patient-reported outcomes between two similar populations with different levels of investigation and treatment. We found that while survivors from RoI were younger, with earlier disease and fewer comorbidities than those from NI, patient-reported outcomes were similar when stratified by disease extent at diagnosis; indeed, very few significant differences were found once adjustment had been made for patient characteristics and treatment. 
Table 3 Patient-reported health utility, health-related quality of life and psychological well-being outcomes-early stage prostate cancer-Rol versus NI

\begin{tabular}{|c|c|c|c|c|c|c|c|c|c|c|c|}
\hline \multirow{2}{*}{$\begin{array}{l}\text { Outcome and } \\
\text { instrument/subscale }\end{array}$} & \multicolumn{2}{|c|}{$\begin{array}{l}\text { Weighted } \\
\text { mean }\end{array}$} & \multicolumn{3}{|c|}{$\begin{array}{l}\text { Univariate model } \\
\text { NI vs Rol }\end{array}$} & \multicolumn{3}{|c|}{$\begin{array}{l}\text { Multivariate model } 1^{*} \\
\text { NI vs Rol }\end{array}$} & \multicolumn{3}{|c|}{$\begin{array}{l}\text { Multivariate model } 2 \dagger \\
\text { NI vs Rol) }\end{array}$} \\
\hline & Rol & NI & Coefficient & $95 \% \mathrm{Cl}$ & p Value & Coefficient & $95 \% \mathrm{Cl}$ & p Value & Coefficient & $95 \% \mathrm{Cl}$ & p Value \\
\hline \multicolumn{12}{|l|}{ Health utility } \\
\hline EQ-5D-5L score & 0.9 & 0.8 & -0.072 & -0.103 to -0.041 & 0.001 & -0.052 & -0.082 to -0.022 & $0.001 \ddagger$ & -0.040 & -0.071 to -0.008 & 0.013 \\
\hline \multicolumn{12}{|c|}{ Health-related quality of life } \\
\hline $\begin{array}{l}\text { QLQ-C30: global } \\
\text { health status }\end{array}$ & 72.5 & 74.1 & 1.549 & -1.367 to 4.466 & 0.298 & 3.318 & 0.400 to 6.237 & 0.026 & 4.063 & 1.024 to 7.101 & 0.009 \\
\hline $\begin{array}{l}\text { QLQ-C30: physical } \\
\text { functioning }\end{array}$ & 85.9 & 80.6 & -5.297 & -8.480 to -2.114 & $0.001 \ddagger$ & -3.357 & -6.361 to -0.352 & 0.029 & -2.029 & -5.103 to 1.046 & 0.196 \\
\hline $\begin{array}{l}\text { QLQ-C30: role } \\
\text { functioning }\end{array}$ & 85.7 & 77.3 & -8.359 & -12.335 to -4.384 & $0.0001 \ddagger$ & -6.781 & -10.742 to -2.821 & $0.001 \ddagger$ & -5.218 & -9.263 to -1.174 & 0.011 \\
\hline $\begin{array}{l}\text { QLQ-C30: emotional } \\
\text { functioning }\end{array}$ & 84.8 & 82.0 & -2.770 & -5.682 to 0.141 & 0.062 & -0.887 & -3.745 to 1.970 & 0.543 & 0.097 & -2.797 to 2.991 & 0.948 \\
\hline $\begin{array}{l}\text { QLQ-C30: cognitive } \\
\text { functioning }\end{array}$ & 83.9 & 81.3 & -2.578 & -5.278 to 0.122 & 0.061 & -0.782 & -3.515 to 1.952 & 0.575 & -0.503 & -3.316 to 2.311 & 0.726 \\
\hline $\begin{array}{l}\text { QLQ-C30: social } \\
\text { functioning }\end{array}$ & 86.1 & 81.1 & -5.004 & -8.488 to -1.520 & 0.005 & -3.283 & -6.803 to 0.237 & 0.068 & -2.437 & -6.097 to 1.222 & 0.192 \\
\hline QLQ-C30: fatigue & 19.9 & 27.2 & 7.299 & 4.178 to 10.421 & $0.0001 \ddagger$ & 5.167 & 2.068 to 8.266 & $0.001 \ddagger$ & 3.893 & 0.703 to 7.082 & 0.017 \\
\hline $\begin{array}{l}\text { QLQ-C30: nausea } \\
\text { and vomiting }\end{array}$ & 3.1 & 3.8 & 0.717 & -0.545 to 1.979 & 0.265 & -0.115 & -1.437 to 1.207 & 0.865 & -0.732 & -2.268 to 0.805 & 0.350 \\
\hline QLQ-C30: pain & 11.1 & 19.4 & 8.264 & 4.882 to 11.645 & $0.0001 \ddagger$ & 6.399 & 3.053 to 9.745 & $0.0001 \ddagger$ & 5.829 & 2.349 to 9.308 & $0.001 \ddagger$ \\
\hline QLQ-C30: dyspnoea & 12.2 & 19.9 & 7.711 & 3.962 to 11.461 & $0.0001 \ddagger$ & 6.125 & 2.382 to 9.869 & $0.001 \ddagger$ & 5.336 & 1.376 to 9.296 & 0.008 \\
\hline QLQ-C30: insomnia & 21.0 & 28.3 & 7.272 & 3.230 to 11.315 & $0.0001 \ddagger$ & 4.995 & 1.018 to 8.972 & 0.014 & 3.588 & -0.565 to 7.741 & 0.090 \\
\hline $\begin{array}{l}\text { QLQ-C30: appetite } \\
\text { loss }\end{array}$ & 5.2 & 7.1 & 1.848 & -0.580 to 4.276 & 0.136 & 0.451 & -1.999 to 2.900 & 0.718 & 0.347 & -2.241 to 2.934 & 0.793 \\
\hline $\begin{array}{l}\text { QLQ-C30: } \\
\text { constipation }\end{array}$ & 11.5 & 11.4 & -0.155 & -3.243 to 2.934 & 0.922 & -1.868 & -4.976 to 1.240 & 0.239 & -1.731 & -4.907 to 1.445 & 0.285 \\
\hline QLQ-C30: diarrhoea & 8.8 & 8.2 & -0.624 & -2.938 to 1.690 & 0.597 & -1.585 & -3.973 to 0.803 & 0.193 & -1.954 & -4.579 to 0.671 & 0.144 \\
\hline $\begin{array}{l}\text { QLQ-C30: financial } \\
\text { difficulties }\end{array}$ & 10.2 & 9.8 & -0.392 & -2.9582 .174 & 0.765 & -1.454 & -4.091 to 1.182 & 0.279 & -1.713 & -4.4601 .034 & 0.221 \\
\hline \multicolumn{12}{|l|}{ Psychological well-being } \\
\hline DASS: distress & 4.9 & 6.4 & 1.559 & 0.403 to 2.715 & 0.008 & 1.062 & -0.095 to 2.219 & 0.072 & 0.652 & -0.529 to 1.834 & 0.279 \\
\hline DASS: anxiety & 3.2 & 4.5 & 1.285 & 0.375 to 2.195 & 0.006 & 0.893 & -0.010 to 1.797 & 0.053 & 0.828 & -0.070 to 1.725 & 0.071 \\
\hline DASS: depression & 4.0 & 4.9 & 0.957 & -0.089 to 2.002 & 0.073 & 0.620 & -0.417 to 1.657 & 0.241 & 0.402 & -0.688 to 1.492 & 0.469 \\
\hline
\end{tabular}


Table 4 Prostate cancer-related physical symptoms-late disease patients

\begin{tabular}{|c|c|c|c|c|c|}
\hline \multicolumn{3}{|c|}{ Stage III/IV-any Gleason } & \multirow{3}{*}{$\begin{array}{l}\text { Univariate model } \\
\text { OR } \\
\text { (NI vs Rol) } \\
\text { (Rol as baseline) }\end{array}$} & \multirow{3}{*}{$\begin{array}{l}\text { Multivariate model } \text { 1* }^{*} \\
\text { OR } \\
\text { (NI vs Rol) } \\
\text { (Rol as baseline) }\end{array}$} & \multirow{3}{*}{$\begin{array}{l}\text { Multivariate model } 2 \dagger \\
\text { OR } \\
\text { (NI vs Rol) } \\
\text { (Rol as baseline) }\end{array}$} \\
\hline \multirow{2}{*}{$\begin{array}{l}\text { Ongoing side } \\
\text { effect }\end{array}$} & \multicolumn{2}{|c|}{ Weighted proportion } & & & \\
\hline & Rol (\%) & NI (\%) & & & \\
\hline Urinary incontinence & 22.2 & 15.9 & $\begin{array}{l}0.65 \\
(0.44 \text { to } 0.97) p=0.035\end{array}$ & $\begin{array}{l}0.66 \\
(0.44 \text { to } 0.99) p=0.047\end{array}$ & $\begin{array}{l}0.88 \\
(0.55 \text { to } 1.41) p=0.591\end{array}$ \\
\hline Loss of libido & $51.6 \ddagger$ & $64.7 \ddagger$ & $\begin{array}{l}1.68 \ddagger \\
(1.22 \text { to } 2.31) p=0.001\end{array}$ & $\begin{array}{l}1.61 \neq \\
\text { (1.16 to } 2.23) p=0.005\end{array}$ & $\begin{array}{l}1.32 \\
(0.92 \text { to } 1.90) p=0.129\end{array}$ \\
\hline Erectile dysfunction & 66.9 & 66.4 & $\begin{array}{l}0.95 \\
(0.68 \text { to } 1.33) p=0.784\end{array}$ & $\begin{array}{l}1.09 \\
(0.77 \text { to } 1.55) p=0.623\end{array}$ & $\begin{array}{l}1.29 \\
(0.87 \text { to } 1.89) p=0.202\end{array}$ \\
\hline Bowel problems & 14.2 & 21.7 & $\begin{array}{l}1.60 \\
(1.07 \text { to } 2.39) p=0.021\end{array}$ & $\begin{array}{l}1.40 \\
(0.90 \text { to } 2.16) p=0.133\end{array}$ & $\begin{array}{l}1.19 \\
(0.75 \text { to } 1.87) p=0.458\end{array}$ \\
\hline $\begin{array}{l}\text { Breast changes } \\
\text { (gynaecomastia) }\end{array}$ & $9.4 \ddagger$ & $23.3 \ddagger$ & $\begin{array}{l}2.80 \ddagger \\
(1.81 \text { to } 4.32) p<0.001\end{array}$ & $\begin{array}{l}3.09 \ddagger \\
(1.94 \text { to } 4.91) p<0.001\end{array}$ & $\begin{array}{l}2.30 \ddagger \\
(1.41 \text { to } 3.73) p=0.001\end{array}$ \\
\hline Hot flashes & $18.8 \ddagger$ & $41.1 \ddagger$ & $\begin{array}{l}2.95 \ddagger \\
(2.08 \text { to } 4.18) p<0.001\end{array}$ & $\begin{array}{l}2.79 \ddagger \\
(1.95 \text { to } 3.99) p<0.001\end{array}$ & $\begin{array}{l}2.33 \ddagger \\
(1.55 \text { to } 3.51) p<0.001\end{array}$ \\
\hline Fatigue & $24.6 \ddagger$ & $39.0 \ddagger$ & $\begin{array}{l}1.93 \ddagger \\
(1.39 \text { to } 2.70) p<0.001\end{array}$ & $\begin{array}{l}1.71 \neq \\
\text { (1.20 to } 2.44) p=0.003\end{array}$ & $\begin{array}{l}1.53 \\
(1.05 \text { to } 2.23) p=0.028\end{array}$ \\
\hline
\end{tabular}

Results are weighted by country, age at diagnosis and time since diagnosis.

*Logistic regression model adjusted for current age, number of comorbidities, time since diagnosis and method of diagnosis.

†Logistic regression model adjusted for above plus prostatectomy, external beam radiotherapy, brachytherapy and hormone therapy records

with missing treatment or method of diagnosis dropped from all models $(n=12)$. Significant difference at $p<0.05$ but with Bonferroni correction applied.

¥Significant difference between countries with Rol as baseline.

NI, Northern Ireland; Rol, Republic of Ireland.

The PCa-specific symptom reported as most distressing to men is urinary incontinence. ${ }^{18} 19$ In this study, current urinary incontinence was reported by $15 \%$ of men who had been diagnosed with early disease and $20 \%$ of those with late disease, irrespective of jurisdiction and thus intensity of investigation. Erectile dysfunction is reported as a long-term irreversible side effect of treatment, ${ }^{20}$ especially following prostatectomy. ${ }^{21}$ The levels of erectile dysfunction-56\% in early disease and $67 \%$ in late disease-were the same in responders from NI and RoI and are similar to those reported in other population-based surveys. ${ }^{22}$ In patients with early disease, only bowel problems, a recognised side effect of radiotherapy, ${ }^{22} 23$ remained significantly higher in NI than in RoI, after adjustment for patient characteristics and treatments. Patients with cancers at other sites, including the colon and rectum, receive radiotherapy to the bowel area; however, colorectal cancer incidence rates and use of radiotherapy as treatment for this cancer are higher in RoI than in NI. ${ }^{24}$ Physical symptoms associated with ADT-breast changes, hot flashes and libido loss-were reported with a similar frequency by men from NI and RoI with early disease but were significantly more common in patients with late disease from NI compared with those from RoI. The almost twofold higher levels of ever ADT reported by men from NI compared with men from RoI were taken into account in the multivariate analysis. We did not, however, have data on the duration, type or dose of ADT used which might have affected the patient-reported outcomes. We further note that no between-country difference was found when the subgroup of men currently on ADT were analysed separately (data not shown).

Outcomes related to HRQoL, including functioning, general cancer symptoms, health utility and psychological well-being, showed only minimal variations between survivors from RoI and NI; in multivariate analyses, pain was reported as higher in NI in patients with early disease; however, using internationally recognised scales, the observed difference in scores (between 19.4 and 11.1) would be considered only minimally clinically significant. ${ }^{25}$ Pelvic pain is an acknowledged side effect of radiation treatment ${ }^{22}$ and this was reported more often by men from NI. This greater usage of radiation in NI, however, was accounted for in the multivariate analysis. The finding might be explained by higher levels of disease progression or poorer control of pain in NI. We did not collect information on recurrence or use of pain control and hence could not explore this further. The significantly higher level of financial difficulties identified by men from RoI is possibly a reflection of cancerrelated out-of-pocket costs borne by patients in RoI. Previous work in RoI, which included PCa survivors, found that cancer-related financial stress and strain is common, ${ }^{26}$ and this may be, in part, a function of the complex mixed public-private healthcare system in operation. Other studies have shown associations between financial burden and psychological well-being and HRQoL among patients with cancer/cancer survivors. ${ }^{27}$ This may in part explain the lower, although not significant, GHSs reported by men in RoI compared 
Table 5 Patient-reported health utility, health-related quality of life and psychological well-being outcomes late stage prostate cancer-Rol versus $\mathrm{N}$

\begin{tabular}{|c|c|c|c|c|c|c|c|c|c|c|c|}
\hline \multirow[b]{3}{*}{ Outcome scale } & \multirow{2}{*}{\multicolumn{2}{|c|}{$\begin{array}{l}\text { Weighted } \\
\text { mean }\end{array}$}} & \multirow{2}{*}{\multicolumn{3}{|c|}{$\begin{array}{l}\text { Univariate model } \\
\mathrm{NI} \text { vs Rol (ie, Rol is baseline) }\end{array}$}} & \multirow{2}{*}{\multicolumn{3}{|c|}{$\begin{array}{l}\text { Multivariate model } 1^{*} \\
\text { NI vs Rol (ie, Rol is baseline) }\end{array}$}} & \multirow{2}{*}{\multicolumn{3}{|c|}{$\begin{array}{l}\text { Multivariate model } 2 \dagger \\
\text { NI vs Rol (ie, Rol is baseline) }\end{array}$}} \\
\hline & & & & & & & & & & & \\
\hline & Rol & $\mathbf{N I}$ & Coefficient & $95 \% \mathrm{Cl}$ & p Value & Coefficient & $95 \% \mathrm{Cl}$ & $p$ Value & Coefficient & $95 \% \mathrm{Cl}$ & p Value \\
\hline \multicolumn{12}{|l|}{ Health utilities } \\
\hline EQ-5D-5L score & 0.8 & 0.7 & -0.061 & 0.102 to 0.020 & 0.004 & -0.030 & 0.071 to 0.011 & 0.151 & -0.027 & 0.071 to 0.017 & 0.233 \\
\hline \multicolumn{12}{|l|}{ Health-related quality of life } \\
\hline C30: global health status & 67.8 & 71.2 & 3.405 & -0.374 to 7.183 & 0.077 & 5.996 & 2.310 to 9.681 & $0.001 \ddagger$ & 5.472 & 1.525 to 9.420 & 0.007 \\
\hline $\begin{array}{l}\text { QLC-C30: physical } \\
\text { functioning }\end{array}$ & 78.6 & 75.2 & -3.432 & -7.457 to 0.594 & 0.095 & 0.476 & -3.450 to 4.402 & 0.812 & 1.174 & -3.174 to 5.522 & 0.596 \\
\hline $\begin{array}{l}\text { QLC-C30: role } \\
\text { functioning }\end{array}$ & 75.7 & 72.2 & -3.520 & -8.653 to 1.613 & 0.179 & 0.140 & -5.055 to 5.335 & 0.958 & 1.355 & -4.423 to 7.134 & 0.645 \\
\hline $\begin{array}{l}\text { QLC-C30: emotional } \\
\text { functioning }\end{array}$ & 81.0 & 82.1 & 1.091 & -2.532 to 4.715 & 0.554 & 3.014 & -0.614 to 6.643 & 0.103 & 3.750 & -0.280 to 7.781 & 0.068 \\
\hline $\begin{array}{l}\text { QLC-C30: cognitive } \\
\text { functioning }\end{array}$ & 79.9 & 79.3 & -0.538 & -4.367 to 3.291 & 0.783 & 1.754 & -1.990 to 5.498 & 0.358 & 1.818 & -2.300 to 5.937 & 0.386 \\
\hline $\begin{array}{l}\text { QLC-C30: social } \\
\text { functioning }\end{array}$ & 76.4 & 76.6 & 0.231 & -4.245 to 4.707 & 0.919 & 2.581 & -1.991 to 7.154 & 0.268 & 2.915 & -2.081 to 7.911 & 0.252 \\
\hline QLC-C30: fatigue & 27.1 & 31.6 & 4.542 & 0.322 to 8.762 & 0.035 & 0.838 & -3.352 to 5.028 & 0.695 & -0.607 & -5.189 to 3.976 & 0.795 \\
\hline $\begin{array}{l}\text { QLC-C30: nausea and } \\
\text { vomiting }\end{array}$ & 6.2 & 5.3 & -0.844 & -3.227 to 1.540 & 0.487 & -1.762 & -4.426 to 0.903 & 0.195 & -1.949 & -4.800 to 0.902 & 0.180 \\
\hline QLC-C30: pain & 17.5 & 23.8 & 6.325 & 1.986 to 10.664 & 0.004 & 3.689 & -0.715 to 8.094 & 0.101 & 2.638 & -2.218 to 7.494 & 0.287 \\
\hline QLC-C30: dyspnoea & 20.3 & 22.9 & 2.611 & -2.213 to 7.434 & 0.288 & -1.720 & -6.391 to 2.951 & 0.470 & -3.083 & -8.216 to 2.050 & 0.239 \\
\hline QLC-C30: insomnia & 26.2 & 26.7 & 0.518 & -4.594 to 5.629 & 0.842 & -2.442 & -7.522 to 2.638 & 0.346 & -3.823 & -9.618 to 1.972 & 0.196 \\
\hline QLC-C30: appetite loss & 8.4 & 9.8 & 1.335 & -1.990 to 4.661 & 0.431 & -0.716 & -4.357 to 2.926 & 0.700 & -1.686 & -5.641 to 2.268 & 0.403 \\
\hline QLC-C30: constipation & 14.4 & 14.3 & -0.069 & -4.036 to 3.898 & 0.973 & -2.397 & -6.641 to 1.847 & 0.268 & -2.738 & -7.258 to 1.783 & 0.235 \\
\hline QLC-C30: diarrhoea & 11.4 & 12.2 & 0.793 & -2.844 to 4.430 & 0.669 & -0.566 & -4.298 to 3.165 & 0.766 & -1.182 & -5.181 to 2.817 & 0.562 \\
\hline $\begin{array}{l}\text { QLC-C30: financial } \\
\text { difficulties }\end{array}$ & 17.9 & 10.4 & -7.454 & -11.176 to -3.731 & $0.0001 \ddagger$ & -8.137 & -11.772 to -4.503 & $0.0001 \ddagger$ & -8.629 & -12.770 to -4.488 & $0.0001 \neq$ \\
\hline \multicolumn{12}{|l|}{ Psychological well-being } \\
\hline DASS: stress & 5.7 & 6.3 & 0.644 & -0.805 to 2.093 & 0.383 & 0.360 & -1.062 to 1.781 & 0.620 & 0.743 & -0.816 to 2.301 & 0.350 \\
\hline DASS: anxiety & 3.9 & 4.4 & 0.477 & -0.641 to 1.596 & 0.402 & -0.151 & -1.292 to 0.991 & 0.796 & -0.086 & -1.342 to 1.170 & 0.893 \\
\hline DASS: depression & 5.1 & 5.7 & 0.581 & -0.871 to 2.033 & 0.432 & 0.080 & -1.366 to 1.526 & 0.914 & 0.172 & -1.431 to 1.775 & 0.833 \\
\hline
\end{tabular}


with men from NI (although no differences were detected in DASS-21 outcomes).

Comparisons between countries with different policies and practices concerning $\mathrm{PCa}$ detection can make a valuable contribution to the debate on use of PSA to test for PCa. We have shown that patient-reported outcomes are very similar in RoI and NI despite different levels of PSA testing and diagnosed PCa. However, it is important to set these findings in the context of the wider population. It has been estimated that between 1994 and 2005, compared with the 1994 disease levels, there were 5938 'extra' cases of PCa diagnosed in RoI and 763 in NI. ${ }^{4}$ Since 2005, the numbers of PCas in the two jurisdictions have continued to rise. As we have shown here and elsewhere, physical side effects, such as erectile dysfunction and incontinence, are common among prostate cancer survivors in Ireland, ${ }^{21}$ echoing studies in other settings. ${ }^{20}$ These side effects can be viewed, in part, as a consequence of widespread PSA testing since, in the absence of testing, many of the men with side effects may never have been detected with PCa or, if they had been detected, this may have been at an older age, so they would have had to live less time with side effects. The burden of side effects, in terms of the numbers (and rates) of men in the population living with these, is greater in RoI than in NI (ie, higher in the population with higher levels of PSA testing). This important population-level health impact of more intensive PSA testing - and the little (at best) impact of PSA testing on mortality ${ }^{4}$-needs to be considered alongside the findings from the current analysis.

\section{CONCLUSION}

Following 20 years of higher levels of PCa detection in RoI than NI, when stage at presentation is taken into account, health outcomes among PCa survivors differed little between countries. However, the increased intensity of investigation has resulted in a population impact with many additional men in RoI having ongoing PCa-related physical symptoms, a risk for all areas with higher levels of testing.

Based on this evidence, the use of PSA to test high numbers of asymptomatic men as occurred in RoI has not reduced mortality compared with NI but has left many more men with side effects. We recommended that men be offered a PSA test only after informed discussion as recommended by current guidelines.

\section{Author affiliations}

${ }^{1} \mathrm{~N}$. Ireland Cancer Registry; Queen's University Belfast, Centre for Public Health, Belfast, N. Ireland

${ }^{2}$ Department of Epidemiology and Public Health, School of Nursing and Midwifery, University College Cork, Cork, Ireland

${ }^{3}$ Department of General Practice, Queen's University Belfast, Belfast, UK

${ }^{4}$ Institute of Health \& Society, Newcastle University, Newcastle-upon-Tyne, UK

Acknowledgements The authors would like to thank all the men who took the time to complete and return the questionnaire. They would also like to thank the IT staff in both registries who extracted the patient data (Colin Fox and Sandra Deady), clinicians in NI for their feedback on the questionnaire development, and the prostate cancer survivors in both jurisdictions who contributed to questionnaire development. The authors also thank Dr Heather Kinnear who facilitated the study setup and project managed data collection in $\mathrm{NI}$, and to Audrey Craven-Lynn, Joanne Clooney, Patricia McDowell, Jennalee Kennedy and Jonathan Mitchell for data coding and entry. They also acknowledge the assistance of the GPs and research nurses who confirmed eligibility of the men and of Dr David Connolly in refining treatment categories. The advice of the project steering group which included patients was valuable.

Contributors ATG, LS and CD were involved in conception of study, funding and ethics. ATG and DD were involved in data analysis. FJD, ATG, LS and GJG were involved in study organisation. All authors were involved in data interpretation and write-up.

Funding The N. Ireland Cancer Registry is funded by the Public Health Agency for Northern Ireland. This study was funded by Prostate cancer UK (N109-03 and NI-PG13-01), Research and Development Office Northern Ireland, the Health Research Board (HRA_HSR/2010/17) with supplemental funding provided by the National Cancer Control Programme in Rol.

Competing interests LS received an unrestricted grant 2011-2012 from Sanofi-aventis for research into predictors of treatment receipt and survival in prostate cancer.

Ethics approval Research Ethics Committees for NI (ORECNI), 10/NIR03/61.

Provenance and peer review Not commissioned; externally peer reviewed.

Data sharing statement Data from this research are available in anonymised format for specified research proposals by emailing a.gavin@qub.ac.uk. The release of data will be conditional on assurance from the secondary researcher that the proposed use of the data is compliant with the MRC Policy on Data Preservation and Sharing regarding scientific quality, ethical requirements and value for money. A minimum requirement with respect to scientific quality will be a protocol describing the purpose, methods and analysis of the secondary research. Results were disseminated to participants on request and are available via Prostate Cancer UK and NICR websites.

Open Access This is an Open Access article distributed in accordance with the Creative Commons Attribution Non Commercial (CC BY-NC 4.0) license, which permits others to distribute, remix, adapt, build upon this work noncommercially, and license their derivative works on different terms, provided the original work is properly cited and the use is non-commercial. See: http:// creativecommons.org/licenses/by-nc/4.0/

\section{REFERENCES}

1. Mc David K, Lee J, Fulton JP, et al. Prostate cancer incidence and mortality rates and trends in the United States and Canada. Public Health Rep 2004;119:174-86.

2. Globocan 2012. Estimated cancer incidence, mortality and prevalence worldwide in 2012, International Agency for Research on Cancer. World health organisation accessed 2016.

3. Harvey $P$, Basuita A, Edersby $D$, et al. A systematic review of the diagnostic accuracy of prostate specific antigen. BMC Urol 2009;9:14.

4. Schröder FH, Hugosson J, Roobol MJ, et al. Screening and prostate cancer mortality: results of the European Randomised Study of Screening for Prostate Cancer (ERSPC) at 13 years of follow-up. Lancet 2014;384:2027-35.

5. O'Dowd A. Offer men in 40s access to PSA test. BMJ 2016;352: i1802.

6. Carsin AE, Drummond FJ, Black A, et al. Impact of PSA testing and prostatic biopsy on cancer incidence and mortality: comparative study between the Republic of Ireland and Northern-Ireland. Cancer Causes Control 2010;21:1523-31.

7. O'Brien K, Comber H, Sharp L. Completeness of case ascertainment at the Irish National Cancer Registry. Ir J Med Sci 2014;183:219-24.

8. Kearney TM, Donnelly C, Kelly JM, et al. Validation of completeness and accuracy of the Northern Ireland Cancer Registry. Cancer Epidemiol 2015;39:401-44.

9. Drummond FJ, Barrett E, Burns R, et al. The number of tPSA tests continues to rise and variation in testing practice persists: a survey of 
laboratory services in Ireland 2008_2010. Ir J Med Sci 2014;183:369-75.

10. UK national screening committee first report of The National screening committee. London: Department of Health, 2002.

11. NHS cancer screening programmes. Prostate cancer risk management. 2008. http://www.cancerscreening.nhs.uk/prostate/ index.html

12. Gavin A, McCarron P, Middleton RJ, et al. Evidence of prostate cancer screening in a UK region. BJU Int 2004;93:730-4.

13. Drummond FJ, Kinnear H, Donnelly C, et al. Establishing a population-based patient-reported outcomes study (PROMs) using national cancer registries across two jurisdictions; the Prostate Cancer Treatment, your experience (PiCTure) Study. BMJ Open 2015;5:e006851.

14. The EuroQol Group. EuroQol-a new facility for the measurement of health-related quality of life. Health Policy 1990;16:199-208.

15. Aaronson NK, Ahmedzai S, Bergman B, et al. The European Organisation for Research and Treatment of Cancer QLQ-C30: a quality of life instrument for use in international clinical trials in oncology. J Natl Cancer Inst 1993;85:365-76.

16. http://www.eortc.be/qol/files/SCManualQLQ-C30.pdf

17. Lovibond SH, Lovibond PF. Manual for the depression anxiety stress scales. 2nd edn. Sydney: Psychology Foundation of Australia, 1995

18. Sharp L, O'Leary E, Kinnear H, et al. Cancer-related symptoms predict psychological wellbeing among prostate cancer survivors: results from the PICTure study. Psychooncology 2016;25:282-91.

19. Litwin MS, Pasta DJ, Yu J, et al. Urinary function and bother after radical prostatectomy or radiation for prostate cancer: a longitudinal, multivariate quality of life analysis from the Cancer of the Prostate Strategic Urologic Research Endeavor. J Urol 2000;164:1973-7.

20. Korfage IJ, Essink-Bot ML, Borsboom GJ, et al. Five-year follow-up of health-related quality of life after primary treatment of localized prostate cancer. Int J Cancer 2005;116:291-6.

21. Gavin AT, Drummond FJ, Donnelly C, et al. Patient reported "ever had" and "current" long term physical symptoms following prostate cancer treatments. BJU Int 2015;116:397-406.

22. Potosky AL, Legler J, Albertsen PC, et al. Health outcomes after prostatectomy or radiotherapy for prostate cancer: results from the prostate cancer outcomes study. J Natl Cancer Inst 2000;92:1582-92.

23. Litwin MS, Sadetsky N, Pasta DJ, et al. Bowel function and bother after treatment for early stage prostate cancer: a longitudinal quality of life analysis from CaPSURE. J Urol 2004;172:515-19.

24. Donnelly DW, Gavin AT, Comber H. Cancer in Ireland 1994-2004. A comprehensive report. Northern Ireland Cancer Registry/National Cancer Registry of Ireland, 2009.

25. Osoba D, Rodriques G, Myles J, et al. Interpreting the significance of changes in health-related quality of life scores. J Clin Oncol 1998;16:139-44.

26. Sharp L, Timmons A. Pre-diagnosis employment status and financial circumstances predict cancer-related financial stress and strain among breast and prostate cancer survivors Supportive Care in Cancer. Support Care Cancer 2016;24:699-709.

27. Sharp L, Carsin AE, Timmons A. Association between cancer related financial stress and strain and psychological wellbeing among individuals living with cancer. Psychooncology 2013;22:745-55. 


\section{Correction}

Gavin AT, Donnelly D, Donnelly C, et al. Effect of investigation intensity and treatment differences on prostate cancer survivor's physical symptoms, psychological well-being and health-related quality of life: a two country cross-sectional study. BMJ Open 2016;6:e012952.

The contributions are incorrect. They should read as follows;

Contributors ATG, LS, CD and FJD were involved in conception of study, funding and ethics. ATG and DD were involved in data analysis. FJD, ATG, LS and GJG were involved in study organisation. All authors were involved in data interpretation and write-up.

Open Access This is an Open Access article distributed in accordance with the Creative Commons Attribution Non Commercial (CC BY-NC 4.0) license, which permits others to distribute, remix, adapt, build upon this work noncommercially, and license their derivative works on different terms, provided the original work is properly cited and the use is non-commercial. See: http://creativecommons.org/licenses/by-nc/4.0/

BMJ Open 2017;7:e012952corr1. doi:10.1136/bmjopen-2016-012952corr1

CrossMark 